Case Report

\title{
Tacrolimus Aggravated Tube Feeding Syndrome with Acute Renal Failure in a Pediatric Liver Transplant Recipient
}

\author{
R. Kula, M. Melter, J. Kunkel, C. Dörfler, S. Alikadic, B. Knoppke, and R. Zant \\ KUNO University Children's Hospital, Regensburg, Germany \\ Correspondence should be addressed to R. Zant; robert.zant@ukr.de
}

Received 9 May 2017; Accepted 24 July 2017; Published 20 August 2017

Academic Editor: Federica Meloni

Copyright (C) 2017 R. Kula et al. This is an open access article distributed under the Creative Commons Attribution License, which permits unrestricted use, distribution, and reproduction in any medium, provided the original work is properly cited.

\begin{abstract}
Acute renal failure can be caused by calcineurin inhibitors (CNIs), due to arteriolopathy and altered tubular function. Within this context, we present the case of a 14-month-old liver transplant recipient who suffered an acute polyuric renal failure during a short episode of hypercaloric feeding. In our case, CNI-induced distal RTA led to nephrocalcinosis and therefore to secondary nephrogenic diabetes insipidus. The diet with high renal solute load consequently resulted in an acute polyuric renal failure with severe hypernatremic dehydration. In conclusion, a hypercaloric diet in children with potentially impaired renal function due to therapy with CNIs requires precise calculation of the potential renal solute load and the associated fluid requirements.
\end{abstract}

\section{Introduction}

Tacrolimus and cyclosporine are widely used calcineurin inhibitors (CNIs) with a narrow therapeutic window and multiple drug-drug interactions [1]. They have the potency to induce renal failure due to acute arteriolopathy. Moreover, CNIs lead to altered tubular function, resulting in an impaired renal concentrating ability [2].

Within this context, we report the case of a pediatric liver transplant recipient who suffered acute polyuric renal failure leading to severe dehydration during a diet with high renal solute load.

Informed consent was obtained from the parents for publication of this report.

\section{Case Presentation}

A 14-month-old girl with a body weight of $7.7 \mathrm{~kg}$ was admitted to our pediatric intensive care unit (PICU) in acute polyuric renal failure including severe hypernatremia, hyperchloremia, hyperkalemia, hyperuricemia, and metabolic acidosis. Clinically she was irritable and appeared only mildly dehydrated. Her heart rate on admission was 150 beats per minute with an arterial blood pressure of 83/43 (63) $\mathrm{mmHg}$. Renal ultrasound on admission revealed bilateral nephrocalcinosis type IIa. Her laboratory findings on admission are summarized in Table 1. The girl was treated with tacrolimus after liver transplantation 7 months prior to admission for extrahepatic biliary atresia. Renal ultrasound before liver transplantation showed a normal finding. She was discharged home from a former hospital stay 8 days prior to this admission with the recommendation for $800 \mathrm{ml}$ Nutrini Energy MultiFibre $^{\circledR}$ (Table 2) a day in addition to complementary feeding. Against medical advice she drank no additional water. Therefore, her calculated water deficit over the last 8 days was $23.6 \%$ of her body weight (Table 3). In PICU the high protein diet was interrupted and the girl was intravenously rehydrated. The average diuresis in the first 12 hours after admission was $8.1 \mathrm{ml} / \mathrm{kg} /$ hour. Additionally, bicarbonate was administered and the antihypertensive therapy with enalapril was paused for 2 days. Under these therapeutic measures the renal function recovered and the serum electrolytes returned to normal values. After reinstating feeding with Nutrini MultiFibre plus oral bicarbonate instead of Nutrini Energy MultiFibre the child was transferred to the normal ward. On day 9 after admission she was discharged home. At the time of discharge the patient's serum urea and creatinine values were within the normal range, her glomerular filtration rate assessed by serum cystatin $\mathrm{C}$ was $76 \mathrm{ml} / \mathrm{min} / 1.73 \mathrm{sqm}$. In the later course immunosuppression was changed from tacrolimus monotherapy to low-dose tacrolimus plus mycophenolate mofetil. 
TABLE 1: Laboratory findings on admission to the pediatric intensive care unit.

\begin{tabular}{lc}
\hline Laboratory findings on admission & \\
\hline Serum pH & 7.19 \\
Serum bicarbonate & $11.8 \mathrm{mmol} / \mathrm{L}$ \\
Serum base excess & $-15 \mathrm{mmol} / \mathrm{L}$ \\
Serum sodium & $170 \mathrm{mmol} / \mathrm{L}$ \\
Serum potassium & $7.4 \mathrm{mmol} / \mathrm{L}$ \\
Serum chloride & $143 \mathrm{mmol} / \mathrm{L}$ \\
Serum calcium & $1.9 \mathrm{mmol} / \mathrm{L}$ \\
Serum phosphate & $2.85 \mathrm{mmol} / \mathrm{L}$ \\
Serum creatinine & $1.6 \mathrm{mg} / \mathrm{dL}$ \\
Serum urea & $364 \mathrm{mg} / \mathrm{dL}$ \\
Serum osmolality (measured) & $425 \mathrm{mmol} / \mathrm{kg}$ \\
Tacrolimus level & $7.7 \mathrm{mcg} / \mathrm{L}$ \\
Urine pH & 5.6 \\
Urine osmolality & $465 \mathrm{mmol} / \mathrm{kg}$ \\
Urine sodium/creatinine ratio & $86(\mathrm{mM}$ based reference: $<58)$ \\
Urine potassium/creatinine ratio & $25(\mathrm{mM}$ based reference: $<68)$ \\
Urine phosphate/creatinine ratio & $18(\mathrm{mM}$ based reference: $<14)$ \\
\hline
\end{tabular}

TABle 2: Nutrini Energy MultiFibre.

\begin{tabular}{lc}
\hline Nutrini Energy MultiFibre & \\
\hline Energy & $1.5 \mathrm{kcal} / \mathrm{ml}$ \\
Protein & $40 \mathrm{~g} / \mathrm{L}$ \\
Sodium & $39,1 \mathrm{mmol} / \mathrm{L}$ \\
Chloride & $40.3 \mathrm{mmol} / \mathrm{L}$ \\
Potassium & $42.2 \mathrm{mmol} / \mathrm{L}$ \\
Calcium & $22.4 \mathrm{mmo} / \mathrm{L}$ \\
Phosphorus & $24.2 \mathrm{mmol} / \mathrm{L}$ \\
Nitrogen & $6400 \mathrm{mg} / \mathrm{L}$ \\
Osmolarity & $315 \mathrm{mosmol} / \mathrm{L}$ \\
Potential renal solute load & $374 \mathrm{mosmol} / \mathrm{L}$ \\
\hline
\end{tabular}

\section{Discussion}

The etiology of calcineurin inhibitor induced nephrotoxicity has not been clearly established yet. It is thought to be multifactorial, resulting from a combination of an increase in vasoconstrictive factors (endothelin and thromboxane), activation of the renin-angiotensin-aldosterone system, reduction of vasodilator factors (nitric oxide and prostacyclin), and formation of free radicals. CNIs also lead to tubular functional alterations and ion homeostasis disturbances like hyperkalemia, hypomagnesemia and magnesium wasting, distal tubular acidosis, and hyperuricemia. Some of the effects of CNIs on tubular function can be explained by reduced expression of the $\mathrm{Na}^{+}-\mathrm{K}^{+}-2 \mathrm{Cl}^{-}$-cotransporter (NKCC2) on the apical membrane of tubular epithelial cells. Decreased expression of NKCC2 would lead to polyuria, nephrocalcinosis, magnesium wasting, and hyperreninemic hyperaldosteronism [5]. As mentioned above, distal RTA is one of several features of nephrotoxicity induced by tacrolimus treatment [2]. Patients with distal RTA have a metabolic acidosis with an inability to acidify the urine appropriately. This type of RTA is caused by impaired distal acidification and is characterized by the inability to lower urinary $\mathrm{pH}$ maximally $(<5.5)$ under the stimulus of systemic acidemia [6]. Hypercalciuria and nephrocalcinosis are typically present. The mainstay of therapy in all forms of RTA is bicarbonate replacement. The base requirement for distal RTAs is generally in the range of $2-4 \mathrm{mEq} / \mathrm{kg} / 24$ hours. Patients with distal RTA should be monitored for the development of hypercalciuria [7]. The defining characteristic of nephrocalcinosis is generalized calcium deposition in the kidney. Nephrocalcinosis can involve the renal medulla or, much less often, the cortex. The most common cause of nephrocalcinosis is increased urinary calcium excretion with or without hypercalcemia. Distal RTA is the most common cause of nephrocalcinosis (particularly in children) due to hypercalciuria without hypercalcemia. The reported prevalence of nephrocalcinosis in patients with distal RTA ranges from 60 to 80 percent. However, it is clinically difficult to differentiate since nephrocalcinosis itself frequently causes defects in distal acidification. Nocturia, polyuria, and polydipsia due to an impaired urinary concentrating ability (nephrogenic diabetes insipidus) may occur in patients with hypercalcemia or medullary nephrocalcinosis of any cause [8]. Recent data support the hypothesis that in vivo external calcium, through activation of calcium-sensing receptors, modulates the expression/trafficking of aquaporin 2 (AQP2). Short-term control of water permeability occurs via vesicular trafficking of $\mathrm{AQP} 2$ and long-term control through changes in the abundance of $\mathrm{AQP} 2$ and $\mathrm{AQP} 3$ water channels. Defective AQP2 trafficking causes nephrogenic diabetes insipidus, a condition characterized by the kidney's inability to produce concentrated urine because of the insensitivity of the distal nephron to vasopressin [9]. The underlying cause of nephrocalcinosis should be determined and treated if possible. No specific treatment has been shown to prevent progression of nephrocalcinosis. Increased fluid intake may be beneficial for all patients with nephrocalcinosis. Among patients with hypercalciuria, urinary calcium excretion may be reduced by dietary modifications that include restriction of animal protein and sodium intake [10]. Infant formulas have a lower protein content and therefore a lower renal solute load compared to products designed for patients aged over 1 year. Children with increased metabolic needs (e.g., after liver transplantation) and/or decreased fluid tolerance may not be able to consume an adequate volume of standard formulas to promote growth. In this instance, a more concentrated formula may be needed. However, a protein intake which accounts for more than $16 \%$ of calories could contribute to azotemia and negative water balance if associated fluid intakes are low. In these cases the caloric density can be increased by utilizing modular additives of carbohydrate or fat because both do not increase the renal solute load. The potential renal solute load does not need to be calculated routinely, but it is important with patients who have medical problems [11]. If healthy infants consume a predominantly liquid diet ad libitum, their ability to excrete unneeded solutes and to maintain water balance is more than adequate [3]. But the renal solute load and fluid balance should be closely monitored if children have a low fluid 
TABLE 3: The patient's calculated water deficit over the last 8 days prior to admission to the pediatric intensive care unit.

Equations

Water intake $=$ food intake $\times$ water content

Water requirement $=($ food intake $\times$ potential renal solute load/age dependent estimated maximal renal concentration capacity $)+$

(insensible water losses $\times$ patient's body surface area)

Water deficit $=$ water intake - water requirement

Case specific calculations

Water intake per day $=0.8 \mathrm{~L} /$ day $\times 0.77 \mathrm{~L} / \mathrm{L}=0.616 \mathrm{~L} /$ day

Water requirement per day $=(0.8 \mathrm{~L} /$ day $\times 374 \mathrm{mOsmol} / \mathrm{L} / 465 \mathrm{mOsmol} / \mathrm{L})+(0.5 \mathrm{~L} /$ day $/ \mathrm{sqm} \times 0.4 \mathrm{sqm})=0.843 \mathrm{~L} /$ day

Water deficit per day $=0.616 \mathrm{~L} /$ day $-0.843 \mathrm{~L} /$ day $=-0.227 \mathrm{~L} /$ day

Water deficit within 8 days $=1.820 \mathrm{~L}$

Percent of body weight $=1.820 \mathrm{~L} / 7.7 \mathrm{~kg} \sim 23.6 \%$

Potential renal solute load (PRSL) refers to solutes of dietary origin that would need to be excreted in the urine if none were diverted into synthesis of new tissue or lost through nonrenal routes. It is calculated by the following equation: PRSL $=$ nitrogen $/ 28+$ sodium + chloride + potassium + phosphorus. The units are in milliosmoles, except for nitrogen, which is total nitrogen in milligrams. Available phosphorus is assumed to be total phosphorus of milk-based formulas and two-thirds of the phosphorus of soy-based formulas. PRSL is expressed as milliosmoles per liter [3]. The renal concentration capacity on admission was $465 \mathrm{mOsmol} / \mathrm{L}$. The insensible fluid losses under normal condition are $0.5 \mathrm{~L} / \mathrm{sqm} /$ day [4].

intake, if they are receiving calorically dense feedings, or if they have increased extrarenal fluid losses and/or an impaired renal concentrating ability. In these children additional water may be required [12].

In summary, renal dysfunction in pediatric liver transplant recipients treated with CNIs like tacrolimus is well known and well documented in the existing literature [13]. The overall prevalence of chronic kidney disease in this population ranges up to $32 \%$ [14]. Renal failure due to nephrocalcinosis in pediatric liver transplantation is usually described in the context of hyperoxaluria; however, information on tacrolimus induced acute renal failure associated with nephrocalcinosis is scarce and to the best of our knowledge this is the first describing report [15]. Previously published reports include early graft failure in an adult kidney transplanted recipient with severe renal calcifications under tacrolimus treatment [16]. A likely pathophysiologic scenario in our case may have been that tacrolimus induced distal RTA led to nephrocalcinosis and therefore to secondary nephrogenic diabetes insipidus. Insufficient water intake in a diet with high renal solute load and further renal impairment due to enalapril treatment consequently resulted in an acute polyuric renal failure with severe hypernatremic dehydration.

\section{Conclusion}

A hypercaloric diet in children with potentially impaired renal function due to therapy with CNIs requires precise determination of the potential renal solute load and the associated fluid requirements. Pediatric liver transplant recipients treated with CNIs should be assessed for nephrocalcinosis and associated impaired renal function at regular intervals.

\section{Abbreviations}

AQP2: Aquaporin 2

CNIs: Calcineurin inhibitors

NKCC2: $\mathrm{Na}^{+}-\mathrm{K}^{+}-2 \mathrm{Cl}^{-}$-cotransporter

PICU: Pediatric intensive care unit
PRSL: Potential renal solute load

RTA: Renal tubular acidosis.

\section{Conflicts of Interest}

The authors of this manuscript have no conflicts of interest to disclose.

\section{References}

[1] Hesselink D. A., van Schaik R. H., van der Heiden I. P. et al., "Genetic polymorphisms of the CYP3A4, CYP3A5, and MDR1 genes and pharmacokinetics of the calcineurin inhibitors cyclosporine and tacrolimus," Clinical Pharmacology \& Therapeutics, vol. 74, pp. 245-254, 2003.

[2] M. Riveiro-Barciela, I. Campos-Varela, J. L. Tovar et al., "Hyperkalemic distal renal tubular acidosis caused by immunosuppressant treatment with tacrolimus in a liver transplant patient: case report," Transplantation Proceedings, vol. 43, no. 10, pp. 40164018, 2011.

[3] S. J. Fomon and E. E. Ziegler, "Renal solute load and potential renal solute load in infancy," Journal of Pediatrics, vol. 134, no. 1 , pp. 11-14, 1999.

[4] J. S. Dallas and T. P. Foly Jr., "Foly TPJr. Thyromegaly," in Pediatric Endocrinology, F. Lifshitz, Ed., p. 663, Marcel Decker, Inc, New York, NY, USA, 5th edition, 2009.

[5] M. Naesens, D. R. J. Kuypers, and M. Sarwal, "Calcineurin inhibitor nephrotoxicity," Clinical Journal of the American Society of Nephrology, vol. 4, no. 2, pp. 481-508, 2009.

[6] J. R. Soriano, "Renal tubular acidosis: the clinical entity," Journal of the American Society of Nephrology, vol. 13, no. 8, pp. 21602170, 2002.

[7] R. W. Chesney, "Rickets associated with renal tubular acidosis," in Nelson textbook of pediatrics, R. M. Kliegman, B. F. Stanton, J. W. Geme, N. F. Schor, and R. E. Behrman, Eds., p. 1811, Elsevier Saunders, Philadelphia, PA, USA, 19th edition, 2011.

[8] G. Procino, L. Mastrofrancesco, A. Mira et al., "Aquaporin 2 and apical calcium-sensing receptor: new players in polyuric disorders associated with hypercalciuria," Seminars in Nephrology, vol. 28, no. 3, pp. 297-305, 2008. 
[9] G. Valenti, G. Procino, G. Tamma, M. Carmosino, and M. Svelto, "Minireview: aquaporin 2 trafficking," Endocrinology, vol. 146, no. 12, pp. 5063-5070, 2005.

[10] L. Borghi, T. Schianchi, T. Meschi et al., "Comparison of two diets for the prevention of recurrent stones in idiopathic hypercalciuria," The New England Journal of Medicine, vol. 346, no. 2, pp. 77-84, 2002.

[11] S. J. Fomon, "Nutrition of normal infants," in Mosby-Year Book, M. O. St. Louis, Ed., vol. 100, Mosby-Year Book, St. Louis, MO, 1993.

[12] N. Nevin-Folino and T. Mayes, "Enteral nutrition," in Handbook of pediatric nutrition, P. Q. Samour and K. King, Eds., pp. 499524, 2005.

[13] R. N. Fine, "Renal function following liver transplantation in children," Pediatric Transplantation, vol. 9, no. 5, pp. 680-684, 2005.

[14] K. M. Campbell, N. Yazigi, F. C. Ryckman et al., "High prevalence of renal dysfunction in long-term survivors after pediatric liver transplantation," Journal of Pediatrics, vol. 148, no. 4, pp. 475-480, 2006.

[15] M. Galanti and A. Contreras, "Excellent renal function and reversal of nephrocalcinosis 8 years after isolated liver transplantation in an infant with primary hyperoxaluria type 1," Pediatric Nephrology, vol. 25, no. 11, pp. 2359-2362, 2010.

[16] P. Esposito, G. Bedino, A. Gallotti, M. Gregorini, T. Rampino, and A. Dal Canton, "Early allograft calcifications after kidney transplantation,” Urology, vol. 79, no. 3, p. e44, 2012. 


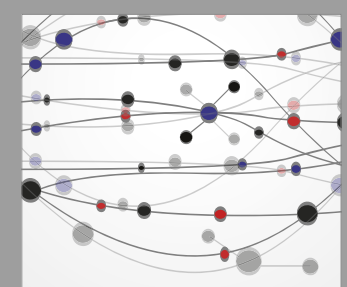

The Scientific World Journal
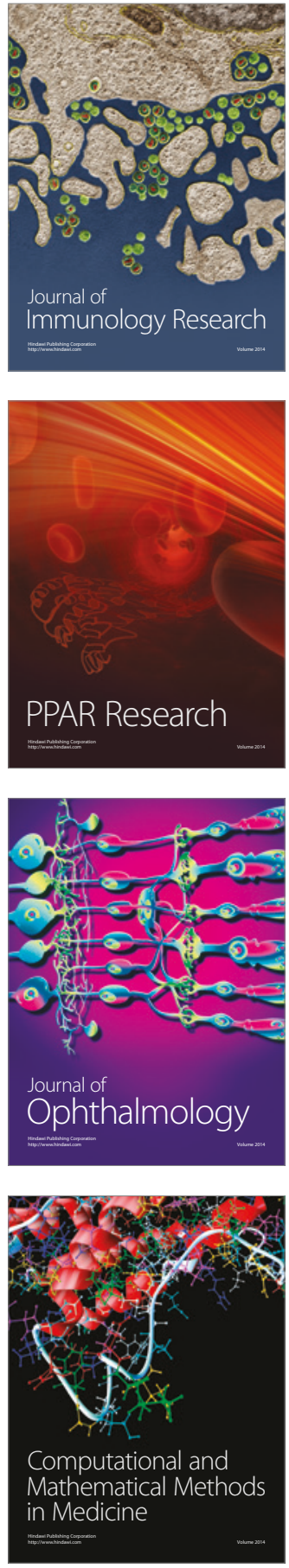

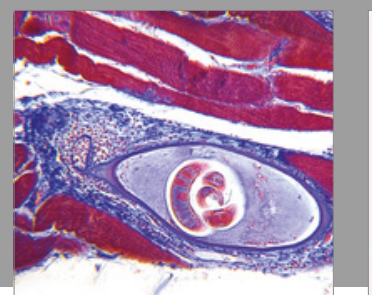

Gastroenterology Research and Practice
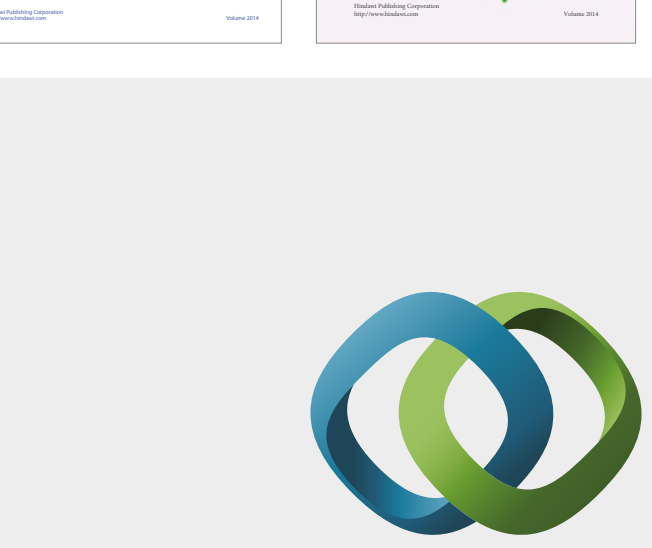

\section{Hindawi}

Submit your manuscripts at

https://www.hindawi.com
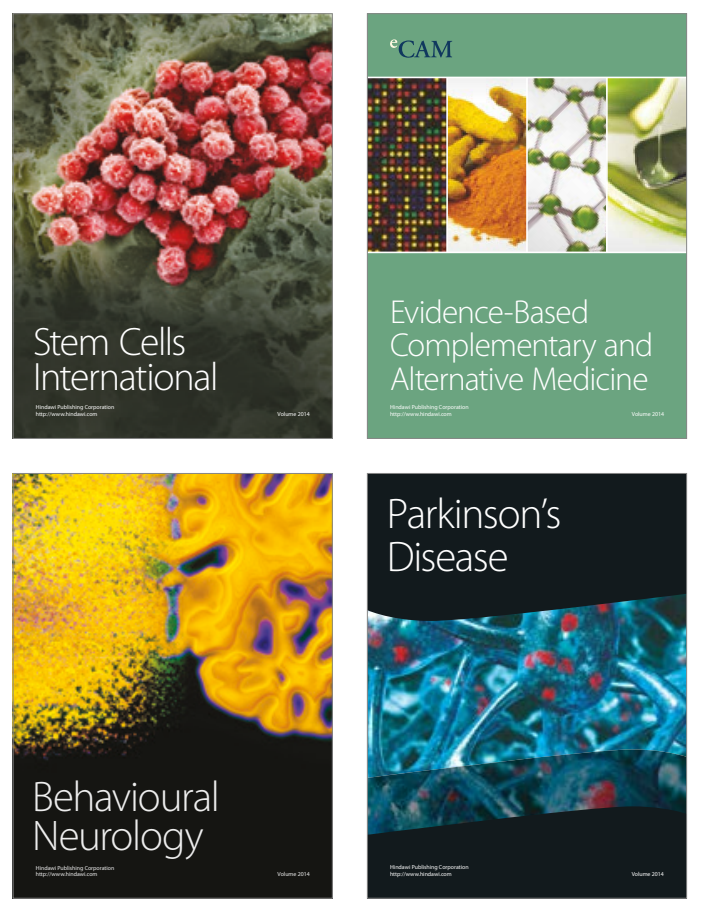
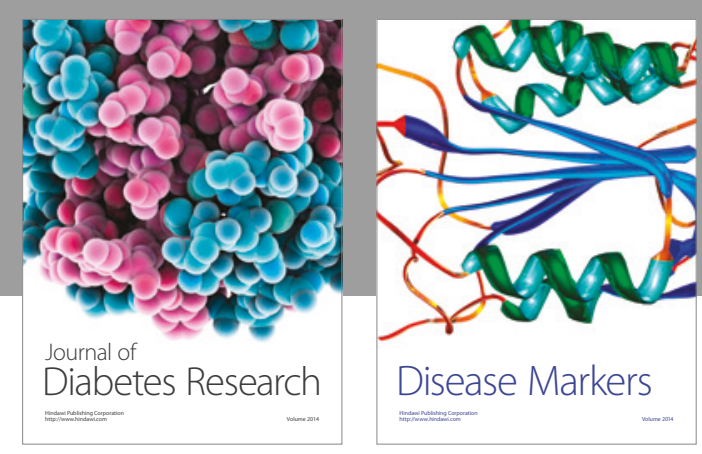

Disease Markers
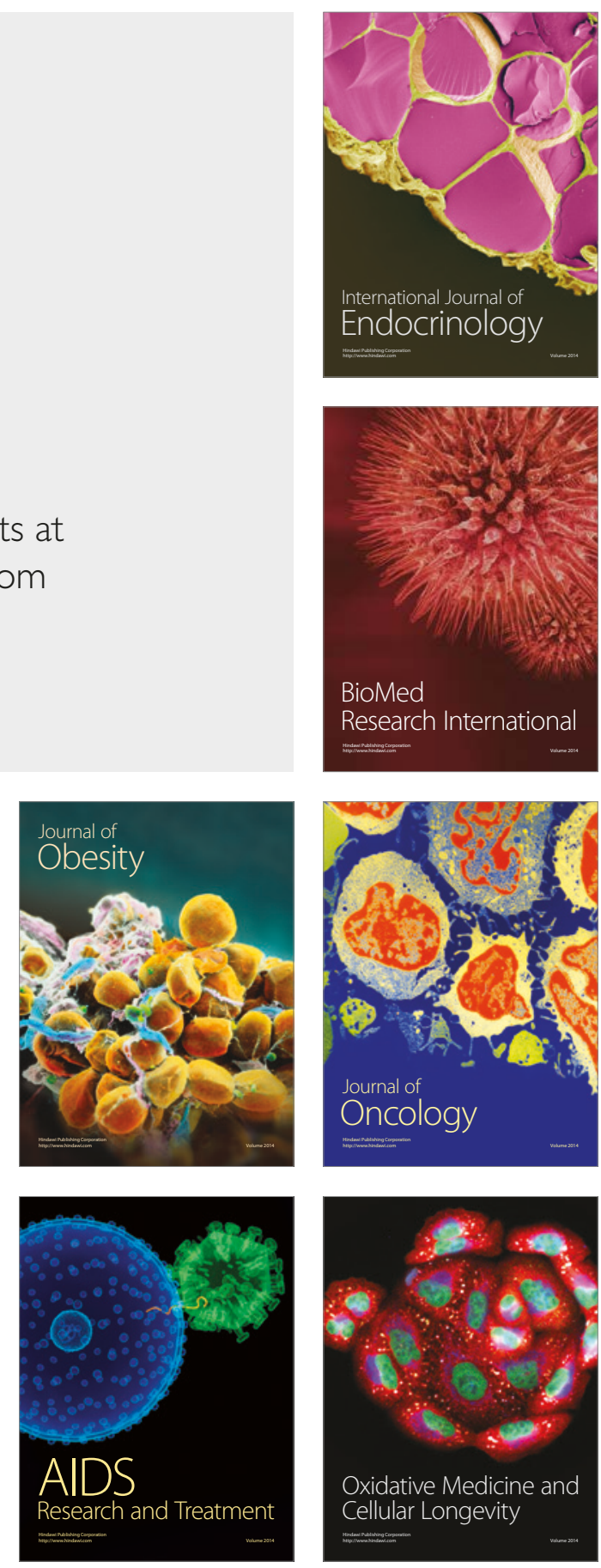